\title{
The phasal polarity marker (a)kona in Manda and its history
}

\section{Bernander, Rasmus}

De Gruyter Mouton

2021

Bernander , R 2021, The phasal polarity marker (a)kona in Manda and its history . in R Kramer (ed.), The Expression of Phasal Polarity in sub-Saharan African language .

Empirical Approaches to Language Typology [EALT] , no. 63 , De Gruyter Mouton, Berlin , pp. 41-72 . https://doi.org/10.1515/9783110646290-004

http://hdl.handle.net/10138/335336

https://doi.org/10.1515/9783110646290-004

unspecified

acceptedVersion

Downloaded from Helda, University of Helsinki institutional repository.

This is an electronic reprint of the original article.

This reprint may differ from the original in pagination and typographic detail.

Please cite the original version. 


\section{The phasal polarity marker -(a)kona in Manda and its history}

Rasmus Bernander

University of Helsinki, Department of Languages,

P.O. Box 24, 00014, Finland

rasmus.bernander@helsinki.fi

\section{Introduction}

Manda (iso 639-3: mgs) is a Bantu language - coded as N11 in Guthrie's (1948) referential classification - spoken by approximately 30000 speakers along the eastern shores of Lake Nyasa (Lake Malawi) in southern Tanzania. ${ }^{1}$ In Manda, the marker -(a)kona, inflected for subject indexation, is employed to express the phasal polarity (PhP) concepts of STILL and NOT YET. This study sets out to describe the formal and functional properties of this marker in Manda. In addition, it will offer an account of its contact-induced origin and current development. It is shown that despite its auxiliary verb-like appearance, -(a)kona does not share the properties of an auxiliary nor does it originate from a lexical verb. Instead, this study argues that it stems from a "copulative", i.e. an element of non-verbal origin which acquired copula-like features through the addition of a subject marker and eventually became specialized as a PhP marker. What is more, this study shows that the PhP marker -(a)kona in Manda is the result of a recent innovation triggered by language contact with a South African Nguni variety, spoken by the invaders and rulers of parts of southern Tanzania in the late $19^{\text {th }}$ century.

This study is organized in the following manner. After this introduction follows section 2 , where a general overview of the complete PhP paradigm in Manda is offered, including a brief presentation of the strategies employed in expressing the related concepts of ALREADY and NO LONGER. The remainder of the paper is devoted to the marker - $(a) k o n a$ and its use in the continuative phasal polarity expressions of STILL and NOT YET. In section 3, the formal and functional characteristics of -(a)kona are described. Section 4 addresses the fact that $-(a)$ kona is a rare marker from a comparative perspective and has an ambiguous categorical status. Section 5 offers an account of the history of - (a)kona and the constructions of which it is a part, tracing its peculiar etymology and disentangling the processes behind its recruitment and further development as a PhP marker. Section 6 contains a brief summary and some concluding remarks.

\section{Expressions of phasal polarity in Manda: A general introduction}

Before embarking on an elaborate presentation and analysis of the specific formal and functional features of -(a)kona, this section sets out to offer some background information on

\footnotetext{
${ }^{1}$ The vast bulk of the data presented in this article has been collected during field work conducted in the Manda speaking area on various occasions throughout the years 2014-2017 for the purposes of my doctoral dissertation (Bernander 2017). The reader is referred to this work for more general information about the Manda language and the Manda speaking community. Some of the results presented in this paper have also been presented there, although many aspects of the analysis have been reinterpreted and strengthened in light of the study by Kramer (2017), as well as by the work of van Baar (1997) and van der Auwera $(1993,1998)$. I would like to direct special thanks to my Manda speaking consultants (plus my additional Mpoto and Matengo informants) as well as to Raija Kramer and an anonymous reviewer for their helpful remarks on a previous draft. Thanks are also due to the audience for their comments on presentations about -(a)kona given at SOAS (in October 2016), at the 14th International Conference of Africanists, in Moscow, Russia (in October 2017) and at the 9th World Congress of African Linguistics in Rabat, Morocco (in August 2018). The usual disclaimer applies.
} 
the language typology of Manda followed by a more general overview of the entire paradigm of phasal polarity expressions found in the language.

\subsection{Some introductory remarks on the language structure of Manda}

In order to facilitate the following description and analysis, this section presents background information on some typological traits of the Manda language, particularly its verbal structure and its strategy of negation, which are notions closely linked to that of phasal polarity. Regarding the verbal structure, Manda adheres to the typical traits of an (Eastern) Bantu language with complex verbal morphology (see e.g. Nurse 2008:28-78), consisting of several affixes marking concepts related to that of phasal polarity - such as tense, aspect and taxis directly on the verb stem. The concatenative verb template in Manda, consisting of various morphological slots dedicated to affixes of certain functional categories can be represented in the following manner (where brackets indicate optionality): ${ }^{2}$

(Pre-SM-) (SM-) (-TAM1-) (-OM-) -ROOT (-EXT) -TAM2

Figure 1. The Manda verbal template

See Bernander (2017:145) for an inventory of the various TAM constructions found in Manda that results from different combinations of affixes in these various slots. It is important to point out that some of these constructions in Manda fluctuate between a realization with the subject marker only and a realization where the vowel of the subject marker coalesces with an $/ a /$ in the TAM1 slot, without there being any semantic differences. This is still a phenomenon in need of further exploration and explanation. It is attested in other languages of this Bantu speaking area as well (e.g. Mpoto N14; Botne 2019). As will be further described in $\S 3.1,-(a) k o n a$ is also affected by this morphophonological fluctuation (hence the $\langle a\rangle$ in brackets).

Manda is a tonal language, but with a highly restricted and predictable tone system consisting of an obligatory high tone on either the stem-initial position or the antepenult and/or penult. Although the assignment on tone may have a contrastive effect, this is only so to a limited extent. As tone plays no important role with regard to the $\mathrm{PhP}$ expressions (or their development) in Manda, this feature is not further discussed here (readers are instead referred to Bernander 2017:54-56).

Of more importance for this specific study is the formation of periphrastic (or complex) verb constructions in Manda. Periphrastic verb constructions are formed in two ways: either as auxiliary + infinitive verb ( deverbal noun), as in (1), or as a serial construction, as in (2), where both verbs are finite and inflected for the same subject. It should be noticed that in the latter case, the first verb is always a copula in (present day) Manda.
(1) ni-bít-a
ku-kıláwók-a ku-Dár
SM1sg-PROSP-FV INF-return-FV LOC17-Dar-es-Salaam
'I am going to return to Dar-es-Salaam'

\footnotetext{
${ }^{2}$ Abbreviations used in this template as well as in the glosses of this article are the following: $1,2,3 \ldots$ (nominal or pronominal) noun class prefix / degree of temporal remoteness; $1,2,3 \mathrm{sg} / \mathrm{pl}$ person; APPL applicative; COMPL completive; CONS consecutive; COP copula; DEM demonstrative; EXT Extension (= derivational suffix); FUT future; FV final vowel; INF infinitive; LOC locative noun class; NEG negative; NOND nondum (= 'not yet'); OM object marker; PER persistive (= 'still'); PFV perfect(ive); POSS possessive pronoun; PROSP prospective; PST past; SM subject marker; TAM tense, aspect, mood. Notice that Manda marks some TAM functions (including future tense) with morphemes in the Pre-SM slot.
} 
(2) kiláwu ya-ní-y-i ni-jéng-íti

tomorrow FUT-SM1sg-COP-FUT SM1sg-build-PFV

'(by) tomorrow I will have built (it)'

This section will be closed with a brief note on the negation system in Manda. Unlike the common Bantu strategy (but in accordance to many other languages in the area), negation is never marked directly on the verb in the present-day version of Manda. Standard negation is marked merely with a free-standing post-verbal particle, either he or lepa lepe (or even lepi).

(3) pícha y-áki i-ka-wớk-a hé

9.picture SM9-POSS3sg SM9-CONS-depart-FV NEG

'her picture didn't go away,

i-tám-a mú-mú-tu i-ka-wớk-a lépa

SM9-sit-FV LOC18-3-head SM9-CONS-depart-FV NEG

it is stuck in my head, it didn't go away'

As illustrated in (3) above, these particles may be used more or less interchangeably. However, lepa lepe is used more frequently (see Bernander 2017:314-315).

\subsection{The Manda PhP paradigm}

Following van Baar (1997:2; see also Kramer 2017; Löbner 1989; Krifka 2000; van der Auwera 1993, 1998; Schadeberg 1990; Heine et al. 1991), the concept of phasal polarity is defined in this paper as the combined notions of contrast in polarity, i.e. the existence or nonexistence of a situation (in contrast to some other situation), with phasal values, i.e. the relative sequencing of these two contrasting situations. In other words, $\mathrm{PhP}$ markers are "structured means of expressing polarity in a sequential perspective" (van Baar 1997:40). Additionally, $\mathrm{PhP}$ expressions are typically associated with the notion of counter-factuality or counter-expectation - i.e. that the contrasting situation runs counter to some presupposition a characteristic specifically put forward as a defining factor in studies on Bantu languages as well as African languages more generally (see e.g. Dimmendaal 1983; Schadeberg 1990;

Heine et al. 1991; Nichols 2011:131; Kramer 2017).

The set of expressions of phasal polarity found in Manda, hence constituting the exhaustive $\mathrm{PhP}$ paradigm in the language, is introduced in (4). ${ }^{3}$

(4) (a) n-ákóna ni-lím-a ng'ónda w-ángu

SM1sg-PER SM1sg-cultivate-FV 3.plot 3-POSS1sg

'I am still cultivating my plot'

(b) n-ákóna ku-lím-a ng'ónda w-ángu

SM1sg-NOND INF-cultivate-FV 3.plot 3-POSS1sg

'I have not cultivated my plot yet'

(c) ni-málí' ku-lím-a ng'ơnda w-ángu

SM1sg-COMPL(<'finish'-PFV) SM1sg-cultivate-FV 3.plot 3-POSS1sg

'I have already cultivated my plot'

(d) ni-lím-a hé ng'ónda w-ángu kávílı

\footnotetext{
${ }^{3}$ It should be pointed out that the interlinear gloss fails to show that the "underlying" subject marker in example (4a) and (4b) is the standard $n i$ - and that the alternative form of the SM1sg in this case stem from a regular type of coalescence with the initial /a/ of $-(a) k o n a$, where $n i-+a>n a-a>n-a$.
} 


\section{SM1sg-cultivate-FV NEG 3.plot 3-POSs1sg anymore(<'again')}

'I am no longer cultivating my farm'

As seen from these examples (more substantially explained with regard to both form and function in the following sections of this article), -(a)kona functions as the substantive element in the semi-schematic constructions expressing both STILL (4a) and NOT YET (4b). From a comparative-conceptual point of view and with regard to the issue of terminology, these constructions with -(a)kona may be associated with two functional categories and subsequently labelled after them. Firstly, the construction in (4a) will be referred to as a "persistive" - a term used by e.g. Nurse (2008) for markers of STILL or constructions that "affirms that a situation has held continuously since an implicit or explicit point in the past up to the time of speaking" (Nurse 2008:165). ${ }^{4}$ Similarly, the construction in (4b) will be referred to as a "nondum" - a term used by Veselinova (2015; Veselinova \& Devos, this volume) for NOT YET markers or constructions "used for the encoding of non-realized expectations for either actions or states" (Veselinova \& Devos, this volume:3). ${ }^{5}$ These two markers may, in turn, be treated together as forming a sub-paradigm of non-telic or continuative $\mathrm{PhP}$ expressions related through internal negation, viz. STILL [NEG [P]] => NOT YET (cf. Kramer 2017). These continuative PhP expressions are the focus of this study and will be further described and analyzed in the remaining sections of this article. The rest of this section offers a brief presentation of the two remaining (telic) $\mathrm{PhP}$ expressions found in Manda. The first one, illustrated in (4c) and discussed in \$2.3.1, makes use of the auxiliary verb -mal- to expresses the notion of ALREADY. The second one, NO LONGER, illustrated in (4d) and further discussed in $\$ 2.3 .2$, is expressed by the adverbial kavılı plus sentence negation.

\subsection{Additional PhP expressions in Manda - a brief description}

\subsubsection{The expression of ALREADY}

The concept of ALREADY is expressed in Manda with the auxiliary -mal-, referred to (and glossed) as a completive marker in Bernander (2017), following Nicolle (2012). The completive in Manda is an auxiliary, transparently derived from the lexical verb -mal- meaning 'finish, complete' (originating from the Proto-Bantu root*-mad-, with reflexes with a similar meaning attested in all Bantu subgroups; cf. Bastin et al. 2002). When functioning as a completive, the auxiliary -mal-is inflected with the perfect(ive) suffix -ili $\sim$-iti (often truncated to - $i$ ' due to the tendency of final syllable deletion in Manda; cf. Bernander 2017:53), occurring with and operating on a second, infinitive verb which conveys the main situation of the proposition. Example (5) illustrates the use of -mal-to express the concept of ALREADY in Manda as a positive, inchoative $\mathrm{PhP}$ expression, with a retrospective focus on the completion of a situation which hold at the time of reference, but which is not anticipated to continue to hold (cf. van der Auwera 1998; Nicolle 2012; Kramer 2017). ${ }^{6}$

\footnotetext{
${ }^{4}$ Although markers labelled as "persistive" and "completive" (used to refer to the expression of ALREADY in this article), are typically treated as aspectual in the (Bantu) literature (rather than explicitly categorized as markers of phasal polarity), I make use of these terms (also in the interlinearization) as they encompass closely interrelated concepts and are thus useful for comparative reasons.

${ }^{5}$ See Bernander (2017:262) and Veselinova \& Devos (this volume) for several alternative terms used for NOT YET constructions in the literature.

${ }^{6}$ These semantic components of retrospective focus and discontinuation overlap with those of NO LONGER (discussed in \$2.3.2). Indeed, according to Schadeberg (1990), a similar completive construction with a 'finish'-verb in Swahili (G42) has 'no longer' as an available second reading. I did not find any evidence of such a second reading in my Manda data. However, -mal- does occur in the language with another conceptually interrelated function, namely that of a resumptive (or tail-head
} 
(5) a-málí’ ku-mál-a ku-télék-a gwáli

SM1-COMPL INF-finish-FV INF-cook-FV 14.ugali

'she has already finished preparing the ugali'

Note that -mal-co-occurs with its own etymon as the lexical verb in this example, one of several clear indications of its specialized status as $\mathrm{PhP}$ marker vis-à-vis its lexical source. Intrinsically, this also illustrates that -mal-may still be used as a full (lexical) verb in Manda (see also (27) for another example of this fact). In contrast to the $\mathrm{PhP}$ expressions with -(a)kona, there are also formal indications of the grammaticalization of -mal-into an auxiliary (as further discussed in section 4).

The recruitment of a terminative verb like -mal- to express the PhP concept of ALREADY is common both across the Bantu speaking area and also cross-linguistically (see e.g. Heine \& Kuteva 2002:134). It should be further noted that the source construction with an inflected auxiliary verb, and with the main, lexical verb in the form of a deverbal noun ( infinitive), also reflects a typical auxiliary construction in Bantu (see e.g. Heine 1993:64-65; Nurse 2008:61; Anderson 2011).

Similarly to what has been pointed out by Vander Klok \& Matthewson (2015; see also Schadeberg 1990; Heine et al. 1991), the auxiliary -mal- in Manda may also carry a reading of counter-expectation, in which case it indicates that the situation has held earlier than expected. ${ }^{7}$ Example (6) is uttered in a context where the speaker is commenting on a passing police officer; the construction with -mal-is used in this instance to express astonishment based on the fact that it is a) only noon and b) the referent is still on duty.

(6) a-málí' kú-nyw-a

SM1-COMPL INF-drink-FV

'he has already (been) drinking ( he is already drunk)?!'

With this said, however, there are some indications that this pragmatic effect of counterexpectation and earliness might undergo neutralization, which, together with the bleaching of the required component of a succeeding negative phase, makes the auxiliary -mal-gaining a function more reminiscent of a perfect. This is an issue in need of further research, but it would seem to adhere to a more general tendency where a verb meaning 'finish' develops into a completive ALREADY and then further to a perfect (see e.g. Bybee et al. 1994:69-81; Heine \& Kuteva 2002:134).

\subsubsection{The expression of NO LONGER}

The final PhP expression to be briefly described is NO LONGER, contrasting with ALREADY by expressing a negative rather than positive state where a situation does not hold, while simultaneously implying a prior point in time where this situation did hold (see e.g. Kramer 2017). This PhP category is arguably articulated in the most deviant manner relative to the other phasal markers in Manda, as it is expressed by a regularly negated predicate and the adverb kavil 'again' (see Persohn this volume, for a corresponding NO LONGER-construction in neighboring Nyakyusa M31). This formal make-up is in contrast with both the de facto auxiliary verb -mal- used for the expression of ALREADY as well as the auxiliary-like STILL/NOT YET-constructions with -(a)kona. The adverb kavilı is derived from the numeral stem -vilI 'two' with the nominal prefix of noun class 12 (used with some productivity for deriving adverbs in Manda). The NO LONGER construction in Manda is illustrated in (7), where

linkage) marker, operating on a second (main/lexical) verb which recapitulates the preceding (and thus no longer holding) event in the discourse (see Bernander 2017:198).

${ }^{7}$ And not later than expected, i.e. it has a reading more similar to the use of English already than to that of Turkish artık (cf. van der Auwera 1998). 
the predicate is negated with one of the two standard negators found in the language, namely the post-verbal particle lepa lepe. (Recall that the other standard negator is he, also a postverbal negator).

(7) va-mánda vá-lím-a lépe ma-pémba kávílı

2-Manda SM2-cultivate-FV NEG 6-millet anymore

'the Manda (community) does no longer cultivate millet'

Thus, kavilı has arguably gained an additional meaning component under negation (van Baar 1997:50), comprising not only a "disrepetitive" reading of NOT AGAIN (to borrow the terminology of van der Auwera 1998), but also a phasal reading of (dis-)continuity, viz. NO LONGER.

\subsection{Some remarks about the complete PhP system in Manda}

After this general overview of all the $\mathrm{PhP}$ expressions found in Manda, some remarks can be made about the paradigm as a whole, based on the criteria provided by Kramer (2017). As seen, there exists a strategy for at least some kind of overt coding of all four variants of phasal polarity in Manda, each node of the $\mathrm{PhP}$ paradigm being represented with a specific expression. This further suggests that Manda is a language with a relatively rigid paradigm of phasal polarity markers. The only example of an element occurring in more than one $\mathrm{PhP}$ construction is $-(a) k o n a$, which is used to express both STILL and NOT YET.

However, these expressions consist of a disparate set of markers occurring in different types of constructions, thus indicating a relatively asymmetric internal paradigmaticity. The $\mathrm{PhP}$ markers have different categorical status, varying not only in the word classes to which they belong but also in the constructional contexts they occur in. Hence, the PhP markers of Manda cannot be "syntactically parallelized" (Kramer 2017:16). As will become clearer in the following more detailed account, this fact relates particularly to the continuative $\mathrm{PhP}$ expressions with -(a)kona, both regarding the ambiguous categorical status of -(a)kona but also the complex formal relationship between the positive and negative constructions, the expression of NOT YET not merely being the negating of its positive counterpart.

\section{PhP expressions with - (a)kona}

After some background information regarding the complete $\mathrm{PhP}$ paradigm in Manda, including a brief presentation of the other (telic) $\mathrm{PhP}$ markers of the language, this section, as well as the remainder of this article, will focus on the two (non-telic) continuative $\mathrm{PhP}$ expressions of STILL and NOT YET. Both concepts are expressed with constructions containing - $(a)$ kona as the substantive element. In this section, the formal characteristics of -(a)kona, as well as its function(s) as a PhP marker, are described in detail.

\subsection{Basic formal characteristics}

The element -(a)kona most typically occurs in a position directly preceding the main predicative expression on which it operates. It is not an invariable form, as it is obligatorily inflected with a subject marker (SM), a prefix regularly used for nominal indexation on verbs in Manda (cp. Figure $1 ; \S 2.1$ ). As touched upon already in $\$ 2.1$, the vowel of the SM prefix almost always coalesces with an / $a$ / in present day Manda, regardless of its original quality, when occurring on the stem /konal. This can be seen in (8), where the SM indexing noun class 9 occurs as $/ y a /$, despite the fact that it "underlyingly" has the form $(y) i-$, i.e. its basic representation consists of the vowel /i/.

(8) yakona

yi-a-kona 
SM9-a-kona

'It is still/not yet...'

However, there is much more free variation with regard to the presence or absence of this $\mathrm{la} /$ in the older Manda sources as well as in the neighboring languages. As far as I have been able to tell, there are no semantic differences in these various allomorphic realizations, which seems to adhere to a more general (morpho-)phonological phenomenon in Manda and its neighbors which, in turn, needs further elucidation (see §2.1).

\subsection{The expression of STILL (-(a)kona in persistive constructions)}

As already touched upon, -(a)kona is used in Manda to express both the positive continuative STILL as well as the negative continuative NOT YET, hence functioning as both a persistive and as a nondum marker in the language. This section addresses the use of $-(a) k o n a$ as a persistive, i.e. its use to express the positive continuation of a situation which already started in the past. This concept is expressed in a construction where $-(a)$ kona directly precedes the predicative expression, typically a lexical verb. As illustrated in (9), in these cases, both -(a)kona and this predicative verb are inflected with an identical subject marker with the same referent.

(9) v-ákóna va-yímb-a nyímbo mu-kanísa

SM2-PER SM2-sing-FV 10.songs LOC18-9.church

'they are still singing songs in church'

However, the main predicative expression of a persistive construction with -(a)kona might also be a non-verbal word, as is the case in (10) below. In these cases, - $(a)$ kona also contributes a copula-like function to the construction. Notice the co-referentiality between the subject and the predicative adjective.

(10) nkóngo góla gw-ákóna gu-chóko

3.tree DEM3 SM3-PER 3-small

'that tree is still small'

In all these constructions, -(a)kona is used to express that the situation, which has already held from an earlier point in time, continues to hold at reference time. In addition to this retrospective component, however, the persistive also contains a prospective component indicating that a change might occur at some point in time in the future, where the given situation does not hold anymore (as discussed by van der Auwera 1998:39-40). Such a prospective element of the termination of the situation is clearly evident in example (11), where the potential time frame is even explicitly expressed. Notice that this is once again an example where the persistive operates on a non-verbal predicate. (For the discussion in $\S 5$, it is also worth pointing out that it is the locative noun prefix and not $-(a) k o n a$ which provides the locative component of this proposition).

(11) n-ákóna ku-Songéa, kóma ni-hoválíl-a wikéndi SM1sg-PER LOC17-Songea but SM1sg-hope-FV 9.weekend 'I'm still in Songea, but I hope that (for the) weekend

$\begin{array}{lll}\text { ya-ní-y-i } & \text { ni-kiláwíki } & \text { ku-Litúhi } \\ \text { FUT-SM1sg-be-FUT } & \text { SM1sg-return.PFV } & \text { LOC17-Lituhi } \\ \text { I will have returned to Lituhi’ } & \end{array}$




\subsection{The expression of NOT YET (-(a)kona in nondum constructions)}

Besides marking positive continuation, -(a)kona is also used in forming the nondum construction in Manda, i.e. the expression of NOT YET. In this case, the typical verbal collocate is not marked finitely but occurs in the infinitive ( deverbal noun) form.
t-ákóna ku-lóngél-a náko
SMlpl-NOND INF-speak.APPL-FV with.him
'we have not spoken with him yet'

That -(a)kona may be used to render the polar meanings of both STILL and NOT YET is not particularly surprising, given the fact that they are semantically "exactly the same", both "retrospectively continuative and prospectively geared towards possible change" (van der Auwera 1998:40). The only difference between the concept of STILL and that of NOT YET is that the polarity of the situation conveyed in the proposition is negative in the latter case. In van Baar's (1997:35) words (see also van der Auwera 1993:627), the nondum marks a "continuation of absence". In other words, it marks that a given situation which did not hold at an earlier point in time does not hold at reference time either. However, there is once again a prospective component of a likely change in the future, where the given situation will hold. Example (13) is a good illustration of this use of -(a)kona in Manda; here it indicates that the bread in question - which has been put in a pot on the fire-place - was not baked at all at an earlier point in time and is not properly baked at the time of reference either, but will (most likely) be well-baked after some additional time in the fire.

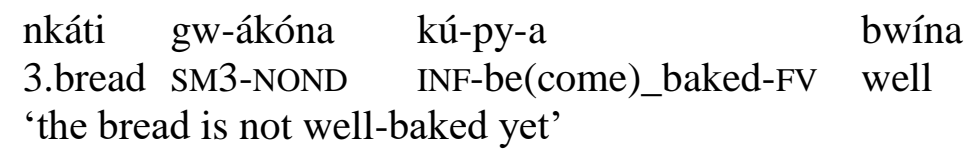

Formally, this overlap in the expression of the persistive and the nondum in Manda adheres to the more general cross-linguistic tendency which stipulates that an element of a positive $\mathrm{PhP}$ expression reappears in its "polarity antagonist" (van Baar 1997:82), a tendency which most typically affects STILL and NOT YET (van Baar 1997:29). However, this connection is usually characterized by the addition of a negator to the positive PhP marker (van Baar 1997:52). It is thus notable that the negative nondum construction with -(a)kona is in fact not negatively marked in any way in Manda. Section 5 elaborates on the historical factors at play leading up to this fact. However, it suffices to mention at this point that it is not unusual per se for nondum markers to replace or be devoid of any negative marking, either crosslinguistically (Veselinova 2015) or in other Bantu languages (see Güldemann 1998; Nurse 2008:148; Abe 2015).

This lack of a negator for forming nondums entails that there is only the formal make-up of the entire construction, and in essence the form of the predicate verb, which decides whether the meaning conveyed is to be interpreted with a positive or negative phasal value. This fact, as explicitly illustrated in the minimal pair in (14), emphasizes the importance of treating these $\mathrm{PhP}$ expressions in Manda holistically as constructions, rather than exclusively focusing on the substantive element of -(a)kona.
(a) ákóna a-lémba
SM1.PER SM1-write-FV
'she is still writing'
(b) ákóna ku-lémb-a
SM1.NOND INF-write-FV
'she hasn't written yet'


In addition, it is also important to point out that $-(a)$ kona with its negative polar reading may be used in isolation as a negative pro-sentence or an answer particle, referring back to a previous proposition (of which -(a)kona agrees in subject marking with an earlier referent). ${ }^{8}$

$$
\begin{aligned}
& \text { (Q:) u-tónd-íti? } \\
& \text { SM2sg-be(come)_tired-PFV } \\
& \text { 'are you tired?' } \\
& \text { (A:) lépa, ni-tónd-í' lépa, n-ákóna } \\
& \text { no SM1sg-be(come)_tired-PFV NEG SM1sg-NOND } \\
& \text { 'no, I'm not tired, not yet' }
\end{aligned}
$$

This kind of patterning was also noted as a salient trait in the cross-linguistic sample of van Baar (1997:295), who even posits a universal on this account, namely: "if a STILL-expression is used as an isolated expression, it is invariably used for the expression of NOT YET". This fact has also been explicitly pointed out for Bende (F12; Abe 2015) also a south-western Tanzanian Bantu language spoken not far from Manda. Recall from §3.2 that -(a)kona can operate on a non-verbal predicate, in which case it expresses a positive, persistive meaning. Taken together, this means that the reading of polarity differs both with regard to the form of a verbal predicate (finite verb $=$ positive reading vs. infinite verb $=$ negative reading) but also with regard to propositions without a verbal predicate (occurrence of non-verbal predicate $=$ positive reading vs. no occurrence of a predicate $=$ negative reading).

\subsection{The marking of counter-expectation with -(a)kona}

This section discusses the component of "counter-expectation" in connection to the $\mathrm{PhP}$ expressions with -(a)kona in Manda, i.e. that the situation depicted in the proposition in some manner contrasts with some presupposition or assumption expressed, either explicitly or implicitly, in the previous discourse. As pointed out by Heine et al. (1991:202; see also van Baar 1997:61), the notion of counter-expectation (or that of "counter-factual scenarios"; cf. Kramer 2017) corresponds inversely to the general semantic make-up of the respective phasal value of a PhP expression. Thus, the persistive, which marks a situation that continues to hold, can also be used to mark the assumed termination of a situation that has not taken place. Similarly, the nondum, which marks a situation that did not hold and continues not to do so, may be used to indicate that an assumed inception and duration of that situation has not taken place. The reading of counter-expectation is, as far as I have been able to tell, not possible to disentangle from a more neutral reading in Manda, but has to be retrieved from the context. Judging from my collection of Manda data (and as also indicated in the examples in $\$ 3.2$ and $\S 3.3)$, a counter-expectational component is far from necessary. In fact, there are virtually no examples in my collection of spontaneous speech (e.g. narratives, expository accounts, conversations etc.) where a positive STILL-construction is used to mark counter-expectation. Thus, the notion of counter-expectation is arguably not central to these PhP-constructions. With that said, both the positive STILL-construction and the negative NOT YET-constructions with -(a)kona are readily available and acceptable for forming propositions with a counterexpectational reading, as illustrated with this pair of elicited sentences, both referring to the same contextual background.

(16) \{My God, I have waited on Michael for half an hour now $\}$

a) ákóna á-v-íli ku-ndindíma

${ }^{8}$ Notice that the double use of lepa in this example reflects the polysemy of this form as both a negative answer particle 'no' and a sentential negator. 
SM1.PERS SM1-be-PFV LOC17-9.toilet

'he is still (sitting) on the toilet?!'

b) ákóna ku-pít-a ku-ndindíma

SM1.NOND INF-go_out-FV LOC17-9.toilet

'he has not yet left the toilet?!'

There are also several instances of counter-expectational nondum expressions in my collection of spontaneous speech in Manda. A good example is the proposition in (17), in which the speaker corrects the misinformed presupposition, previously expressed by the addressee, that the referent (the speaker's son) holds the position of a police officer.

(17) lépa, ákóna kú-y-a polísi

no SM1.NOND INF-be-FV 1a.police_officer

'no, he is not a police officer yet'

In fact, however, the referent is studying to become a police officer. Thus, this construction with -(a)kona also expresses the prospective aspect connected to this pair of $\mathrm{PhP}$ markers (as discussed in $\$ 3.2$ and \$3.3), in this case that the situation - although not holding at the moment - most likely will hold in the future.

While on the topic of counter-expectation, it should be added that the positive persistive construction with -(a)kona may be negated through standard negation. ${ }^{9}$ In this case the reading is similar to the $-(a) k o n a+$ infinitive construction - i.e. the nondum - as it portrays the situation as not having taken place either in the past or at reference time. However, this construction puts more focus on the neglect itself. That is, it highlights the pertaining nonimplementation of the situation encompassed in the predicative expression, rather than the situation itself. Moreover, it is speaker-oriented. Thus, it behaves in these senses similarly to van Baar's $(1997: 2,35,168)$ characterization of the comparable English expression of still not. However, it seems to differ in the sense that it does not necessarily express the speaker's disbelief, but rather runs counter to the hopes or expectations of the addressee (cf. Schadeberg 1990; Nurse 2008:166). Notice that it continues to stand in relation to the focus on different phases of STILL and NOT YET. Thus, unlike (18), where the implementation of the act is delayed but there is an intention to fulfil it, (19) instead conveys that it is exactly the intention not to fulfil the act which persists.

(18) t-ákóna ku-bít-a ku-sheléhe

SM1pl-PER INF-go-FV LOC17-9.party

'we have not gone to the party yet'

\{'but we intend to go there, we are just late'\}

(19) t-ákóna ti-bít-a lépa ku-sheléhe

SM1pl-PER SM1pl-go-FV NEG LOC17-9.party

'we are still not going to the party'

\{'we have decided not to go and we are keeping that promise (still)'\}

\footnotetext{
${ }^{9}$ In fact, it is acceptable to apply standard negation also to the nondum construction, resulting in a reading similar to a proximative or immediate future. Such a construction has only been elicited, however, and there are none in the spontaneous data.
} 


\subsection{The interrelation of -(a)kona with expressions of TAM}

Except for subject marking, -(a)kona cannot be inflected for tense, aspect or mood (TAM). However, it is possible to anchor both of the continuative $\mathrm{PhP}$ expressions in an utterance time different from the "here and now" of the present by placing them in a periphrastic construction. Positive persistives of this kind are formed by shifting the tense inflection of the following predicate verb from the present tense to the past or the future, the latter temporal reference being illustrated in (20). Negative nondum constructions are formed with a preceding copula verb $-y$ - 'be(come)' inflected for tense. This results in highly complex, 3word predicative constructions, as seen in example (21), which illustrates a past tense construction with a negative polarity reading. Persistive constructions with a non-verbal predicate are also formed with the preceding copula verb $-y$-carrying the proper tense marking, as seen in (22).

$$
\begin{array}{ll}
\text { n-ákóna } & \text { ya-ni-yímb-áyi } \\
\text { SM1sg-PER } & \text { FUT-SM1sg-sing-FUT }
\end{array}
$$

'I will still be singing'
ni-ka-y-í'
n-ákóna
kú-ly-a
SM1sg-PST1-be(come)-PFV
SM1sg-NOND
INF-eat-FV
'I hadn't eaten yet'

(22) ni-ka-y-í'

$$
\text { n-ákóna mw-ána }
$$

SM1sg-PST1-be(come)-PFV SM1sg-PER 1-child

'I was still a child'

With regard to the notion of aspect, it should be noted that $-(a) k o n a$ in its use as a persistive may in fact be compatible with the perfect(ive), as illustrated in (23).

However, in analogy with what has been pointed out by Persohn $(2017: 21,114,127,133$, 2019) for Manda's neighbor Nyakyusa (M31), such constructions are only possible when the lexical verb encodes a resultant state (i.e. in this case 'be full'). A persistive construction with -(a)kona and a verb in the perfect(ive) without a lexicalized resultant state, like the punctive -fik- 'arrive' in (24), is thus considered ungrammatical. As illustrated in (25) and (26), however, such a verb is compatible with -(a)kona in a negative persistive construction as well as in the nondum construction.

$$
\begin{aligned}
& \text { ** t-ákóna tu-fík-íli } \\
& \text { SM1pl-PER SM1pl-arrive-PFV } \\
& \text { (25) t-ákóna tu-fík-íli lépe } \\
& \text { SM1pl-PER SM1pl-arrive-PFV NEG } \\
& \text { 'we have still not arrived' } \\
& \text { (26) t-ákóna ku-fík-a } \\
& \text { SM1pl-NOND INF-arrive-PFV } \\
& \text { 'we have not arrived yet' }
\end{aligned}
$$

It should be stressed that although constructions where -(a)kona is used outside the realm of the present imperfective are acceptable, as exemplified in this section, there are strikingly 
few examples like these in my collection of spontaneous speech. ${ }^{10}$ To this it should be added that it seems that -(a)kona is blocked altogether from being used with the subjunctive mood, as there are no examples of such constructions in my corpus and speakers also reject such constructions as unacceptable.

\subsection{A note on additional, non-phasal uses of -(a)kona}

Adhering to the more general trait of $\mathrm{PhP}$ markers as exhibiting a "multiplicity of uses" (van der Auwera 1998:26), -(a)kona has other, yet interrelated, uses in Manda outside the realm of phasal polarity.

There are two additional functions associated with -(a)kona in Manda. Firstly, -(a)kona may be used as a hypotactic conjunction expressing 'before'. In this case, -(a)kona occurs in a construction formally identical to the nondum construction, i.e. it (directly) precedes a verb which occurs in the infinitive/deverbal noun form, as illustrated in $(27)^{11}$.

$$
\begin{aligned}
& \text { a-woy-1́li ku-nyúmba ákóna ku-mál-a li-héngu } \\
& \text { SM1.PST2-return(home)-PFV LOC17-9.home SM1.before INF-finish-FV 5-work } \\
& \text { 'she returned home before finishing the work' }
\end{aligned}
$$

The difference between this construction and the nondum construction is the dependent status of the clause in which -(a)kona occurs itself. Similarly, the main semantic difference relates to the fact that the negative situation encompassed in an adverbial clause with -(a)kona as a conjunction is directly linked to the situation expressed in the main clause predicate, rather than related to a discourse-based presupposition. That a $\mathrm{PhP}$ marker additionally functions as a conjunction is common typologically (van Baar 1997:275-276, 291) and it appears that a relationship between a nondum and 'before' is an especially common semantic relationship of this kind (Veselinova \& Devos, this volume).

In addition to its function as a subordinating conjunction, $-(a)$ kona inflected with the subject marker of a locative noun class - typically that of class 16 - in collocation with the adjective -choko(pi) 'small, little', modifying and agreeing with -(a)kona, expresses the meaning 'soon'. This is illustrated in (28).

$$
\begin{array}{lll}
\text { ya-u-sóv-i } & \text { p-ákóna } & \text { pa-chokópi } \\
\text { FUT-SM14-be.lost-FUT } & \text { LOC16-PER } & \text { LOC16-soon } \\
\text { 'it will soon be lost (the flour)' } &
\end{array}
$$

Notice that this construction with -(a)kona differs from those previously discussed, in that, in this case, it does not agree with a nominal constituent but may only occur with a fixed and more expletive-like locative subject marker, thus producing a more independent and invariable expression. What is more, unlike other constructions with -(a)kona, this adverbial phrase occurs after the predicate verb, in the canonical syntactic position of a prototypical adverb in Manda.

These additional functions are clearly related to those of phasal polarity, although it is not obvious that they are necessarily derived from either of the $\mathrm{PhP}$ expressions or if they represent individual pathways of change (adhering to van Baar's 1997:342 "plane model"). What is obvious, however, and what once again is important to point out, is the fact that it is the construction as a whole - of which -(a)kona only forms a part - which decides the specific

\footnotetext{
${ }^{10}$ This tendency may be strengthened by the wide referential range of the present tense in Manda, which may be used in a manner similar to a "historical present" as well as for marking assertive future. ${ }^{11}$ Notice that the infinitive verb in this example happens to be -mal- which in this case is not used as a marker of ALREADY but as a full (lexical) verb (cf. the discussion in §2.3.1).
} 
semantic instantiation of this polysemic element and, in extension, the interpretation of the entire proposition.

\section{The ambiguous categorical status of -(a)kona}

Although -(a)kona can be accounted for quite straightforwardly as a $\mathrm{PhP}$ marker, there are also several peculiarities connected to this element. To begin with, it is a rare marker of STILL and NOT YET from a comparative point of view. As far as I know (see also Veselinova \& Devos, this volume) a persistive and/or nondum construction with (cognate forms of) -(a)kona only appears in Manda and a limited set of its closest affiliates. Furthermore, as already touched upon in \$2.1, Bantu languages are renowned for being both agglutinative and verbcentered, resulting in a rich set of verbal morphology. Consequently, it is typically the case across the Bantu family that at least the notion of STILL is expressed with a "persistive" verb prefix (Nurse 2008:145), which has even been reconstructed for Proto-Bantu (Meeussen 1967) and typically surfaces as $-k a$ - around the area where Manda is spoken (Güldemann 1996:138-143, 1998; Nurse 2008:243; Persohn, this volume).

It is often the case, however, that this persistive prefix does not attach directly to the lexical verb root but to a copula (or some other light verb), forming part of a complex construction that is, a construction similar to the one described for $-(a) k o n a$, where the main situation of the proposition is expressed in a subsequent second verb, or, alternatively, operates on a nonverbal predicative expression. Example (29) from Zaramo (G33) and example (30) from Chewa (N31b), are cases in point.

tu-ha-li tu-gul-a
SM1pl-PER-COP SM1pl-buy-FV
'we are still buying' [Zaramo]
ba-ka-li $\quad$ ku-tali
SM2-PER-COP LOC17-far
'they are still far away' [Chewa]
[Güldemann (1998:167)]

As well as being a rare instantiation of a STILL/NOT-YET-marker in Bantu, -(a)kona also has an ambiguous categorical status. As may be deduced from the presentation of - $(a)$ kona in the previous section, it is "auxiliary"-like, i.e. it appears and behaves similarly to an auxiliary verb when taken at face value. It is used to express notions commonly associated with a verbal marker (as mentioned in the previous paragraph) and it agrees with the subject in a manner characteristic of verbs. ${ }^{12}$ In addition, -(a)kona ends with a vowel /a/, reminiscent of the "default" final vowel of Bantu verb stems (cf. Nurse 2008:261). The constructions with -(a)kona are also syntagmatically similar to the complex verbal constructions expressing continuative phasal polarity found in other Bantu languages (Veselinova \& Devos, this volume; Nurse 2008:145-148). Despite these superficial correspondences, however, it is hard to account for - $(a) k o n a$ as an auxiliary, whether in relation to other auxiliaries in Manda or to the cross-linguistically valid criteria outlined by van Baar (1997:221-224; see also Heine 1993; Anderson 2008, 2011).

To begin with, -(a)kona lacks verbal properties, of which at least some would be expected to persist in an auxiliary. Thus, except for subject indexation, - (a)kona cannot carry any other inflectional morphology typical of a verb in Manda. It may not be inflected with other types

\footnotetext{
${ }^{12}$ Notice furthermore that given van Baar's (1997:244-245) criteria of word class categorization in relation to $\mathrm{PhP}$ markers, the fact that $-(a)$ kona is regularly and variably inflected disqualifies it as a particle, whereas the fact that it can be used to modify nominal constituents (as non-verbal predicates) also excludes it from being characterized as an adverb.
} 
of nominal indexation such as relative markers or object markers, nor can it be derived with extensions, i.e. suffixes marking various syntactic and/or semantic reconfigurations. Similarly, it may not be (directly) inflected for TAM, as discussed in $\$ 3.5$ above.

Crucially, -(a)kona cannot be traced etymologically to any lexical verb, neither in Manda, nor from a comparative stance. In fact, -(a)kona cannot be linked to any language-internal linguistic material at all.

In addition to its lack of these general verbal characteristics, - (a)kona also lacks the specific morpho-syntactic traits characterizing auxiliary verbs in Manda (cf. Bernander 2017). Consequently, it fails van Baar's (1997:220-221) conditions of a "grammaticalized" PhP expression, that is, a construction which has been altered both semantically and formally, resulting in a new form-meaning pair that differs from its source. This lack of formal adaption becomes evident when -(a)kona is compared to the completive -mal- (described in §2.3.1), which is both a PhP marker and a bona fide auxiliary. For example, as illustrated in (31) (also in (10), (11), §3.2 above), -(a)kona may occur with and operate on non-verbal constituents. This contrasts with auxiliaries in Manda, which, in their acquired status as grammaticalized function words, exclusively operate on verbs. Consequently, an auxiliary like -mal- may only collocate with a non-verbal constituent when it has its original, lexical meaning, as illustrated in (32).

(31) ákóna nchúmba w-ángu SM1sg-PER 1.fiancé 1-POSS1sg 'she is still my fiancé'
u-mál-í'
má-lávi gh-ángu
SM2sg-finish(**COMPL)-PFV 6-peanuts 6-POSS1sg
'you have finished my peanuts' / **'you have already my peanuts'

Moreover, there is a general restriction on auxiliaries in Manda - which is, indeed, a formal indication of their decategorialized status relative to their lexical etymon - that they cannot stand alone but must always occur together with the verb they operate on. This diagnostic, which conforms to van Baar's (1997:238) isolation tests, is another indication of whether a PhP expression is grammaticalized or not. (See also Bernander 2017 for a more elaborate account of this syntactic phenomenon regarding auxiliaries in Manda). As illustrated in the ellipsis construction in (33), when the auxiliary -mal-is used to convey the PhP concept of ALREADY, it cannot stand alone (A2) but must co-occur together with the verb expressing the main event of the clause (A1). However, as seen in (34), -(a)kona is not affected by this restriction, i.e. both $\mathrm{A} 1$ and $\mathrm{A} 2$ are acceptable (elided) answers to the question in (34) (see also (15) in §3.3).

$$
\begin{aligned}
& \text { (Q:) a-mál-í } \quad \text { ku-yás-a ki-tábu? } \\
& \text { SM1-COMPL-PFV INF-lose-FV } \\
& \text { 'has she already lost the book?' }
\end{aligned}
$$
(A1:) eh, a-mál-í'
ku-yás-a
/ (A2:)**a-mál-í(ti)
yes SM1-COMPL-PFV INF-lose-FV
I SM1-COMPL-PFV
'yes, she has already lost it'
'she has already (lost it)'
(Q:) w-ákóna ku-hémél-a ki-tábu ki-nyipa?
SM2sg-NOND INF-buy-FV 7-book 7-new
'haven't you bought a new book yet?'

(A1:) éna, n-ákóna ku-hémél-a / (A2:) éna, n-ákóna 
yes, SM1sg-NOND INF-buy-FV / yes, SM1sg-NOND

'no (lit. yes), I have not bought (it yet)' / 'no (lit. yes), I have not bought (it yet)'

The remainder of this study sets out to clarify these described synchronic peculiarities of -(a)kona by accounting for its origin and historical background.

\section{The etymology of -(a)kona and its recruitment as a PhP marker}

As explained in the presentation of -(a)kona so far in this article, it is in many ways an unusual $\mathrm{PhP}$ marker, given its rare form, its ambivalent word class membership, as well as the fact that it may be used to express both positive and negative statements without the use of any negator. A proper account of these formal and functional peculiarities of this PhP marker in Manda demands an explanation of its origins and subsequent development, which, in turn, will facilitate an understanding of its idiosyncratic form and behavior. However, the semasiological background of -(a)kona is complex, and an extensive account of its reconstruction is, unfortunately, beyond the limited scope of this article. While this section offers a brief account, more socio-historical contextualization, illustrations and discussions can be found in Bernander (2017:16-17, 19-29, 266-271). Fundamentally, what a historicalcomparative approach does is that it identifies two important traits of the element - $(a)$ kona (+ subject marking): i) -(a)kona ultimately derives from a word and a construction which was borrowed from South African Nguni, and ii) -(a)kona is structurally a "copulative", i.e. an element of non-verbal origin used as a copula which became a PhP marker through joint processes of semantic generalization and specialization in Manda and its neighbors.

The borrowing scenario of -(a)kona relies, to begin with, on the socio-historical fact that a large group, initially of South African origin and speaking a Nguni (S40) variety, arrived in the area of southern Tanzania where Manda is spoken, in the mid- $19^{\text {th }}$ century. This arrival occurred at a time when Manda and the neighboring varieties had not consolidated as ethnic communities and subsequently as individual languages (Park 1988). The Nguni invaded and subjugated the previous inhabitants, whose descendants became part of the Nguni ( Ngoni) community but did not shift to the medium of communication of their rulers. Instead, a diglossic situation prevailed between "Old Ngoni" and "New Ngoni". Whereas Old Ngoni indeed was a Nguni (S40) language, albeit altered in relation to its sister languages in South(ern) Africa (cf. Doke 1954:237), New Ngoni was mainly a blend of various southern Tanzanian tongues spoken by the previous inhabitants and other captives from the area who were assimilated into the Ngoni community. It is New Ngoni which constitutes Tanzanian Ngoni (N12) as spoken today (see especially the lexico-statistical and phonological evidences for such a conclusion put forward in Nurse 1988; see also Ngonyani 2001, 2003:1-3;

Rosendal \& Mapunda 2014; Mous 2019 and further references in these works). New Ngoni is not only Manda's closest neighbor but is also considered its closest affiliate. ${ }^{13}$ Old Ngoni has become extinct and is generally understood as having left few linguistic traces in New Ngoni or in neighboring languages like Manda (see e.g. Nurse 1985, 1988; Ngonyani 2001).

Nonetheless, linguistic remnants do exist from this Nguni variety, and the comparative data suggests that -(a)kona is one of them.

That -(a)kona in Manda was borrowed from Nguni is indicated in table 1, which compares the functional and constructional range (viz. "type" I-IV) of the element ${ }^{\circ} \mathrm{kona}^{14}$ in Old

\footnotetext{
${ }^{13}$ This conclusion is based on both lexico-statistics and phonology (Nurse 1988; Gray \& Roth 2016) as well as on speakers' self-perception of mutual intelligibility and cultural similarity (Anderson et al. 2003).

${ }^{14}$ This element, with the same semantic features as in Old Ngoni, surfaces as $\langle k h o n a\rangle$ with $\langle\mathrm{h}\rangle$ in Zulu and other South African Nguni languages, where it marks aspiration. Aspiration, which is a non-
} 
Ngoni, as well as in Manda and its closest affiliates of the N10 subgroup, including New Ngoni. As a point of reference and in order to make the differentiation between the southern Tanzanian varieties and the Nguni varieties clearer, I have added Zulu (the presumed original language of Old Ngoni according to Ebner 1939; Doke 1954:237) and Malawian Ngoni (another Nguni offshoot from the $19^{\text {th }}$ Century emigration) to this table. ${ }^{15}$

This comparative table indicates the source and the direction of diffusion and semantic shift of which this element has been the subject. The types in the first row refer to meaning, word class belonging and/or constructional type. Type III is not different in meaning from type II. However, the construction in which it occurs is different, being a more complex construction, viz. a concatenation with the subject marker resulting in a more complex, copulative, function. A 'no' entails that the meaning described above does not exist in a variety and 'yes' that it does. Question marks represent less certain cases. It should be stressed that this table only shows whether or not a reflex of ${ }^{\circ} \mathrm{kona}$ is attested with a certain meaning in a given language. ${ }^{16}$ Similarly, the table does not mark the strategies used instead of ${ }^{\circ} \mathrm{kona}$ for expressing continuative phasal polarity.

contrastive feature in Manda and New Ngoni, as well as in the other N10 languages, is not marked in Spiss' grammar on Old Ngoni, although it is not clear if this is really due to phonological loss or is merely an orthographic shortcoming (see Doke 1954:237).

${ }^{15}$ I have not added Zambian Ngoni nor Mozambican Ngoni to this list. For Zambian Ngoni, I have no other source than Brelsford (1956:95) who merely notes that "Linguistically Ngoni was a dialect of Zulu but it has disappeared [...] and widely dispersed Ngoni usually use the language of the area they now occupy". Mozambican Ngoni is not included as it a) denotes an originally southern Tanzanian variety spoken by a community who only adapted the name Ngoni as they left southern Tanzania for the northern provinces of Niassa and Cabo Delgado in Mozambique roughly 80 years ago (Kröger 2013) and b) appears to use a different continuative PhP marker than a reflex of -(a)kona (cf. Kröger n.d.).

${ }^{16}$ As the sources on most of these languages are non-exhaustive, the risk that the non-existence of a certain meaning may be due to a lacuna in the source(s) rather than to its non-existence in the language must of course be taken into consideration. 


\begin{tabular}{|c|c|c|c|c|c|c|}
\hline \multicolumn{2}{|c|}{ Meaning type } & $\begin{array}{l}\text { I. } \\
\text { EMPHATIC } \\
\text { PRONOUN: } \\
\text { 17-ona } \\
\text { '(the place) } \\
\text { itself' }\end{array}$ & $\begin{array}{l}\text { II. ADVERB } \\
\text { 'here, } \\
\text { there'; } \\
\text { 'now, } \\
\text { then' }\end{array}$ & $\begin{array}{l}\text { III. } \\
\text { COPULATIVE } \\
\text { 'S be } \\
\text { (here/present)' }\end{array}$ & $\begin{array}{l}\text { IV. } \\
\text { STILL - } \\
\text { NOT } \\
\text { YET }\end{array}$ & Sources \\
\hline \multirow[t]{3}{*}{$\begin{array}{l}\text { NGUNI } \\
\text { (S40) }\end{array}$} & Zulu & yes & yes & yes & no & $\begin{array}{l}\text { Grout (1859), } \\
\text { Doke (1927), } \\
\text { Cope (1984) }\end{array}$ \\
\hline & $\begin{array}{l}\text { Malawian } \\
\text { Ngoni }\end{array}$ & yes & yes & yes & no & Elmslie (1891) \\
\hline & Old Ngoni & yes & yes & yes & no(?) & $\begin{array}{l}\text { Spiss (1904), } \\
\text { Doke (1954) }\end{array}$ \\
\hline \multirow[t]{4}{*}{ N10 } & $\begin{array}{l}\text { New } \\
\text { Ngoni }\end{array}$ & no & yes(?) & yes & yes & $\begin{array}{l}\text { Spiss (1904), } \\
\text { Ebner (1939), } \\
\text { Ngonyani } \\
(2003)\end{array}$ \\
\hline & Matengo & no & no & yes & yes & $\begin{array}{l}\text { Häflinger } \\
\text { (1909), } \\
\text { Zimmer (n.d.), } \\
\text { Yoneda (2006), } \\
\text { Kayuni (p.c.) }\end{array}$ \\
\hline & Mpoto & no & no(?) & no(?) & yes & $\begin{array}{l}\text { Makwaya } \\
\text { (p.c.), Botne } \\
(2019)\end{array}$ \\
\hline & Manda & no & no & no & yes & $\begin{array}{l}\text { field notes, NT } \\
\text { (1937), Missa } \\
\text { Mbalafu (n.d.) }\end{array}$ \\
\hline
\end{tabular}

Table 1. The meaning and use of -kona in Old Ngoni and N10 ${ }^{17}$

As suggested by this table, kona ultimately stems from a free-standing pronoun (type I), the "absolutive" and "emphatic" pronoun -ona inflected in the locative class 17 . Notice that neither this pronoun nor the inflectional paradigm it is derived from exist in the N10 languages. As a matter of fact, Ebner (1955:160) makes explicit reference to this pronoun type when discussing the linguistic differences between Old and New Ngoni. As further seen in the table, this pronoun has an additional function as a non-deictic locational temporal adverb in the Nguni varieties, including Old Ngoni (type II). Importantly, just as in the other Nguni languages, kona was also used as a "copulative" (type III) in Old Ngoni, that is, a nonverbal constituent "conjugated as the verb proper by the employment of subjectival concords" (Doke 1927:225). Consider example (35):

\footnotetext{
${ }^{17}$ Spiss (1904) mostly contains information on Old Ngoni, but also an accompanying word list of New Ngoni (i.e. modern Tanzanian Ngoni; N12). Therefore, this work is cited in both columns.
} 
(35) kuse kuwa u-kona

be.good that SM2sg-here

'it is good that you are here' [Old Ngoni; Spiss (1904:305)]

The ability to derive copulatives in this manner is described as a distinctive feature of Nguni languages in general (see Doke 1954:79-80). Compare example (36) taken from present day Zulu.

(36) aba-ntu ba-khona bodwa

2-people 2-be.here 2.alone

'the people are here alone' [Zulu; Cope (1984:85)]

However, forming copulatives in this manner is not a productive strategy in the southern Tanzanian languages. Thus, there is neither a pronoun kona, nor is there a strategy of turning this pronoun into a copulative in these languages. Recall furthermore that no inherent source for -(a)kona could be found in Manda. Still, there is an overlap in meaning between kona of Old Ngoni and kona of the N10 languages. This strongly suggests that -(a)kona was copied into the N10 languages in the form of a locative adverb (II), together with the constructional strategy of forming a copulative by the addition of a subject marker (III). ${ }^{18}$ However, only at a later stage (type IV), and exclusively in the N10 languages, did the element get extended in use and specialized into a marker of phasal polarity. Thus, this is a function it never acquired in the donor language Old Ngoni nor in other Nguni languages (which make use of other strategies, mainly verb prefixes, to mark these concepts). ${ }^{19}$ However, the fact that Spiss at least on one occasion translates kona as 'still there' suggests that this inference already existed in Old Ngoni (see Spiss 1904:371). In any case, positing this copulative as the source would adhere to the typologically salient fact that a PhP item initially stems from borrowed material, which does not necessarily have the function of expressing phasal polarity in the donor language (van der Auwera 1993:628-629, 1997:67-73; van Baar 1997:126-129). Another cross-linguistic generalization which can be made regards the typical source meaning(s) of the etymon in question. Firstly, the original meaning(s) of -(a)kona are largely consistent with the typical source meanings posited for a persistive (van Baar 1997:90-95; van der Auwera 1993, 1998; Heine \& Kuteva 2002:218). More generally, it complies with the essential strategy of employing copulas and locative markers for all kinds of grammatical expressions devoted to the notion of ongoing activity, most typically that of progressive aspect (see e.g. Nurse 2008:259; Bybee et al. 1994:129).

Importantly, positing that -(a)kona is an element of non-verbal origin would explain many of the formal peculiarities characterizing the persistive/nondum in Manda. As described in $\S 4,-(a) k o n a$ cannot be linked to any lexical verb source in Manda and, with the exception of verbal subject indexation, it lacks verbal features, whether those of a lexical or an auxiliary verb. This absence of verbal properties may thus be explained by the simple fact that $-(a)$ kona does not stem from a verb but an adverb (and ultimately a pronoun) being used as a verb. In addition, the persistent copula-like status of $-(a)$ kona explains the fact that (a)kona as a PhP

\footnotetext{
${ }^{18}$ There are also some possible diachronic factors at play with regard to the N10 languages which the table does not show. Thus, for both Matengo and New (Tanzanian) Ngoni, only the older sources from the early $20^{\text {th }}$ century mention the meaning/usage pattern of type II and III along with type IV, whereas the sources from the early $21^{\text {st }}$ century only mention the phasal polarity meanings.

${ }^{19}$ Various constructions with the verbal prefix -se- but also - $k a$ - (cp. the $-k a$ - discussed in $\S 4$ ) are attested for the expressions of STILL/NOT YET both in Old Ngoni (Spiss 1904:296) and today's Zulu (Cope 1984).
} 
marker can collocate with non-verbal constituents as well as occurring in isolation, in contrast with a more dependent auxiliary. Taking these facts together, the development of the copulative -(a)kona into a persistive can quite straightforwardly be accounted for as a case of semantic extension.

A trickier question to answer regards the motivation behind recruiting - $(a) k o n a$ as a $\mathrm{PhP}$ marker. A plausible explanation from a functional point of view would be the need in Manda (and its neighbors) for a more expressive (counter-factual?) persistive/nondum, given the ample indications that what appears to be the reflex of the original persistive (a reflex of the $-k a$ - described in $\$ 4$ ) has become generalized into a marker of simultaneous taxis and/or imperfective aspect (see e.g. Bernander 2017:199-201). That there exist remnants of an earlier continuative $\mathrm{PhP}$ marker would put further weight to the hypothesis that $-(a)$ kona was (relatively) recently introduced. From a formal point of view, the recruitment of -(a)kona might have been facilitated by the fact that its copulative configuration resonated well in morpho-syntactic terms with the features of the original persistive/nondum construction, which also was complex and which, in addition to having a persistive prefix, contained a copula.

\subsection{On the loss of an explicit negator in the nondum construction}

As noted in earlier parts of this article, - $(a) k o n a$ is used in Manda to express NOT YET without any overt negator. This phenomenon is not unheard of across the Bantu speaking family (see e.g. Veselinova \& Devos, this volume, Nurse 2008:147-148; Güldemann 1998; Abe 2015). It is usually explained as originating from a shift from "affirmative meaning to negative inference" (Nurse 2008:148), induced by the inceptive status and thus non-factual reading of an infinitive verb. That is, ' $\mathrm{S}$ (is) still to $\mathrm{X}$ ' $>$ ' $\mathrm{S}$ have not yet $\mathrm{X}$ ' (where $\mathrm{S}=$ the Subject and $\mathrm{X}$ $=$ the situation expressed by the infinitive verb). However, although this might be the case for other Bantu languages with an analogous nondum construction, this is most likely not what has happened in Manda. The historical and comparative data instead clearly indicates that in fact there used to exist an overtly expressed negator of the form na- $n g a-$, but that it has disappeared from present-day Manda. Consider table 2 below, which compares the presentday nondum construction in Manda (in the very last column) with the formal realization of the same PhP concept in both of Manda's closest affiliates, as well as in the older Manda sources.

\begin{tabular}{|l|l|l|}
\hline Language & Form & Source \\
\hline Mpoto (N14) & SM-(a)kona \# nga-INF-B-a & Makwaya (pers. comm) \\
\hline $\begin{array}{l}\text { Matengo } \\
\text { (N13) }\end{array}$ & SM-(a)kona \# ngaa INF-B-a & $\begin{array}{l}\text { Häflinger (1909:184), Yoneda } \\
(2006: 99), \text { Kayuni (pers. comm. })\end{array}$ \\
\hline Ngoni (N12) & SM-(a)kona \# na-INF-B-a & $\begin{array}{l}\text { Ngonyani (2003:87), Ebner } \\
(1939: 33-34)\end{array}$ \\
\hline $\begin{array}{l}\text { Manda (N11) } \\
\text {-Historical } \\
\text { data }\end{array}$ & SM-(a)kona \# n(g)a-INF-B-a & NT (1937), Missa Mbalafu (n.d.) \\
\hline $\begin{array}{l}\text {-Present } \\
\text { data }\end{array}$ & SM-(a)kona \# (Ø-)INF-B-a & field notes \\
\hline
\end{tabular}

\section{Table 2. The nondum construction in Manda in comparison}

The bolded element in this table is the negative prefix, which - as can clearly be seen - is present in all the other languages. The only exception to this tendency to have a pre-verbal 
nasal-initial negator - and thus the only variety which lacks a negative prefix in the construction of the nondum - is Manda as spoken today, where the negator is absent (symbolized in the table with a zero morph). Thus, compare the Manda nondum construction with that of its closest affiliate Ngoni.

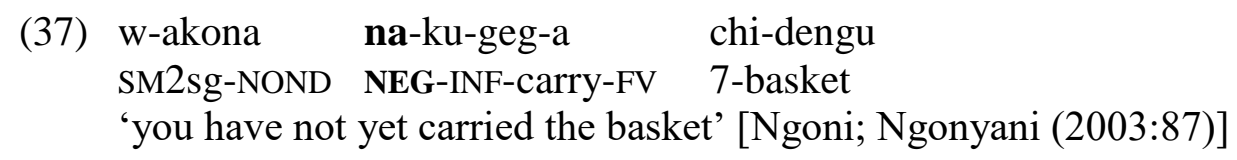

Importantly, the table shows that a negative prefix of a similar shape and position to that of its affiliates also existed even in earlier varieties of Manda. Example (38), from the translation of the New Testament (1937), illustrates this fact.
saa y-ake y-akona na-ku-hich-a
9.hour 9-POSS3sg SM9-NOND NEG-INF-come-FV
'his hour had not yet come' [NT (1937); John 7:30]

Taking these comparative and diachronic facts into account strongly suggests that the constructional make-up of the nondum in Manda is partly the result of the omission of a previously occurring negative prefix. It should be pointed out that this reconstructed construction with a negator more readily adheres to the dual conceptualization of PhP markers (Löbner 1989; Krifka 2000) and to a typologically more salient formal realization (van Baar 1997:98), where the concept of NOT YET is expressed by internal negation of STILL. This suggests that there used to be a more coherent systematization of the continuative PhP expressions in Manda, based on a compositional relationship of internal negation.

So why has this negator been lost in Manda? The answer to that question is related to the obsolete status of this negator in general in Manda. ${ }^{20}$ Unlike the other N10 languages, which still make use of this negative prefix also in other contexts other than nondum constructions, $n(g) a$ - has been completely levelled out as part of a Jespersen's Cycle scenario and in presentday Manda is replaced by post-verbal particles (see Bernander 2017:318-320 for further details about this omission). ${ }^{21}$

\section{Summary and conclusions}

This article has described expressions of phasal polarity in Manda, with the focus on the PhP expressions STILL (the persistive) and NOT YET (the nondum), both concepts being expressed with the marker -(a)kona. It has described the (extensive) functional and formal range of this phasal marker and, in addition, the etymology of -(a)kona, the mechanics behind its recruitment into a $\mathrm{PhP}$ marker and its further development and reconfigurations within this paradigm. As argued, -(a)kona originates from borrowed material which can be traced to a Nguni copula-like construction ("copulative"), construed by the application of a verbal subject marking to a locative/temporal adverb (ultimately a locative pronoun), which, as a local innovation in Manda (and other N10 languages), became extended in meaning into a PhP marker.

\footnotetext{
${ }^{20}$ In present day Manda, this negator only surfaces as a petrified part of the negative copula núkúya < 'na-kuya 'NEG.to be' (and probably also in the negative relative -anga).

${ }^{21}$ A plausible additional driving force for the omission of the negative prefix in the specific nondum construction is the fact that the final syllable of -(a)kona and the negative prefix are tautophonic, the omission of the negator being triggered by a more general preference in Manda for haplology, i.e. the deletion of one of two identical adjacently occurring syllables.
} 
This scenario of both context-induced change and further semantic development within the recipient language(s) further explains why Manda (and other N10 languages) has this comparatively unusual $\mathrm{PhP}$ marker, with an idiosyncratic form and unusual morpho-syntactic behavior.

Interestingly, these findings would seem to contradict the general understanding that the Nguni variety ("Old Ngoni") spoken in Tanzania had a limited impact on the speech communities of southern Tanzania - including on Manda - and calls for the reassessment and further scrutiny of this contact situation and its linguistic effects.

\section{References}

Abe, Yuko. 2015. Persistive in Bende - On the grammaticalization path. Asian and African Languages and Linguistics 9. 23-44.

Anderson, Gregory. 2006. Auxiliary verb constructions. Oxford: Oxford University Press.

Anderson, Gregory. 2011. Auxiliary verb constructions in the languages of Africa. Studies in African Linguistics 40(1\&2). 1-409.

Anderson, Heidi, Susanne Krüger \& Louise Nagler. 2003. A sociolinguistic survey of the Manda language community. Ms, SIL Tanzania.

Bastin, Yvonne, Coupez, André, Mumba, Évariste \& Schadeberg, Thilo. (eds.). 2002. Bantu lexical reconstructions 3 / Reconstructions lexicales bantoues 3. Tervuren: Royal Museum for Central Africa.

http://www.africamuseum.be/collections/browsecollections/humansciences/blr

Bernander, Rasmus. 2017. Grammar and grammaticalization in Manda: An analysis of the wider TAM domain in a Tanzanian Bantu language. $\mathrm{PhD}$ thesis. University of Gothenburg.

Botne, Robert. 2019. Chimpoto N14. In: Mark Van de Velde, Koen Bostoen, Derek Nurse, Gérard Philippson (eds.) The Bantu Languages. 692-732. London: Routledge.

Bybee, Joan, Revere Perkins \& William Pagliuca 1994. Evolution of grammar: tense, aspect, and modality in the languages of the world. Chicago: University of Chicago Press.

Cope, A. T. 1984. An outline of Zulu grammar. African Studies 43(2). 83-102.

Doke, Clement. 1927. Textbook of Zulu grammar. Cape Town: Masker Miller Longman.

Doke, Clement. 1954. The Southern Bantu languages. London/New York: Published for the International African Institute by Oxford University Press.

Ebner, Elzear. 1939. Kisutu Grammatik. Mission Magagura, Tanganyika. Peramiho: St. Benedictine Mission. Ms.

Ebner, Elzear. 1955. The history of the Wangoni. Peramiho. Ndanda: Benedictine Publications.

Gray, Hazel \& Tim Roth. 2016. New perspectives on the genetic classification of Manda (Bantu N.11). SIL Electronic Working Papers 2016-001. Dallas: SIL International.

Grout, Lewis. 1859. The Isizulu: A Grammar Of The Zulu Languages. Kessinger Publishing.

Guthrie, Malcolm. 1948. The classification of the Bantu languages. London: Oxford University Press.

Güldemann, Tom. 1996. Verbalmorphologie und Nebenprädikationen im Bantu: Eine Studie zur funktional motivierten Genese eines konjugationalen Subsystems. Bochum: Brockmeyer.

Güldemann, Tom. 1998. The relation between imperfective and simultaneous taxis in Bantu: late stages of grammaticalization. In Catherine Griefenow-Mewis Fiedler \& Brigitte Reineke (eds.), Afrikanische Sprachen im Brennpunkt der Forschung: 
Linguistische Beiträge zum 12. Afrikanistentag Berlin, 3.-6. Oktober 1996, 157177. Köln: Rüdiger Köppe.

Heine, Bernd. 1993. Auxiliaries: Cognitive forces and grammaticalization. New York: Oxford University Press.

Heine, Bernd, Ulrike Claudi \& Friederike Hünnemeyer. 1991. Grammaticalization: A conceptual framework. Chicago: University of Chicago Press.

Heine, Bernd \& Tania Kuteva. 2002. World lexicon of grammaticalization. Cambridge: Cambridge University Press.

Häflinger, Johannes. 1909. Kimatengo Wörterbuch. Mitteilungen des Seminars für Orientalische Sprachen zu Berlin, 12. 31-214.

Kramer, Raija. 2017. Position paper on phasal polarity expressions. Ms, University of Hamburg. https://www.aai.uni-hamburg.de/afrika/php2018/medien/positionpaper-on-php.pdf

Krifka, Manfred. 2000. Alternatives for Aspectual Particles: Semantics of still and already. In Lisa J. Conathan, Jeff Good, Darya Kavitskaya, Alyssa B. Wulf \& Alan C.L. Yu (eds.), Proceedings of the Twenty-Sixth Annual Meeting of the Berkeley Linguistics Society: General Session and Parasession on Aspect, 401-412. Berkeley: Berkeley Linguistics Society.

Kröger, Heidrun. 2013. Demonstratives in Mozambican Ngoni. Paper presented at the $5^{\text {th }}$ International Conference on Bantu languages, Paris 12-15 June.

Kröger, Heidrun. (n.d). Notes on Ngoni. Ms, SIL Mozambique.

Löbner, Sebastian. 1989. 'Schon - erst - noch': An integrated analysis, Linguistics and Philosophy 12(2). 167-212.

Meeussen, A. E. 1967. Bantu grammatical reconstructions. Africana linguistica 3. 79-121. Missa Mbalafu. [The gospel in Kimanda]. n.d. Likoma: UMCA press.

Mous, Maarten. 2019. Language contact. In: Mark Van de Velde, Koen Bostoen, Derek Nurse, Gérard Philippson (eds.), The Bantu Languages. 355-380. London: Routledge.

New Testament in Manda. 1937. Kilagano kya hino kya Bambo witu nu njokosi witu Yesu Kristo. London: British and Foreign Bible Society.

Ngonyani, Deogratias. 2001.The Evolution of Tanzanian Ngoni. In Derek Nurse (ed.), Historical language contact, 321-353. Köln: Rüdiger Köppe.

Ngonyani, Deogratias. 2003. A Grammar of Chingoni. München: Lincom Europa.

Nichols, Peter. 2011. A morpho-semantic analysis of the persistive, alterative and inceptive aspects in siSwati. PhD thesis, SOAS (School of Oriental and African Studies, London).

Nicolle, Steve. 2012. Diachrony and grammaticalization. In Robert Binnik (ed.), The Oxford Handbook of Tense and Aspect, 370-397. Oxford: Oxford University Press.

Nurse, Derek. 1985. Review of Moser, R, Aspekte der Kulturgeschichte der Ngoni in der Mkoa wa Ruvuma, Tansania. Journal of African Languages and Linguistics 7(1). 207-11.

Nurse, Derek. 1988. The diachronic background to the language communities of southwestern Tanzania. Sprache und Geschichte in Afrika 9. 15-115.

Nurse, Derek. 2008. Tense and aspect in Bantu. Oxford: Oxford University Press.

Park, George. 1988. Evolution of a regional culture in East Africa. Sprache und Geschichte in Afrika 9. 117-204.

Persohn, Bastian. 2017. The verb in Nyakyusa: A focus on tense, aspect and modality (Contemporary African Linguistics 2). Berlin: Language Science Press.

Persohn, Bastian. 2019. Aspectuality in Bantu: On the limits of Vendler's categories. Linguistic Discovery 16(2). 1-19. 
Rosendal, Tove \& Mapunda, Gastor. 2014. Is the Tanzanian Ngoni Language threatened? A Survey of Lexical Borrowing from Swahili. Journal of Multilingual and Multicultural Development. 35(3). 271-288.

Schadeberg, Thilo. 1990. Schon - noch - nicht - mehr: Das Unerwartete als grammatische Kategorie im Kiswahili, Frankfurter Afrikanistische Blätter 2. 1-15.

Spiss, Cassian. 1904. Kingoni und Kisutu. Mitteilungen des Seminars für Orientalische Sprachen zu Berlin, 3. Abteilung: Afrikanische Studien VII. 270-414.

van Baar, Tim. 1997. Phasal polarity. Dordrecht: Foris Publications.

van der Auwera, Johan. 1993. 'Already' and 'still': Beyond duality. Linguistics and philosophy 16(6). 613-653.

van der Auwera, Johan. 1998. Phasal adverbials in the languages of Europe. In Johan van der Auwera \& Dónall P.O. Baoill (eds.): Adverbial constructions in the languages of Europe, 25-145. Berlin/New York: Mouton de Gruyter.

Vander Klok, Jozina \& Lisa Matthewson. 2015. Distinguishing already from perfect aspect: A case study of Javenese wis, Oceanic Linguistics 54(1). 172-205.

Veselinova, Ljuba. 2015. Not-yet expressions in the languages of the world: a special negator or a separate cross-linguistic category? Paper presented at Diversity Linguistics: Retrospect and Prospect, Max Planck Institute for Evolutionary Anthropology, Leipzig. May 1-3, 2015.

Yoneda, Nobuko. 2006. Vocabulary of the Matengo language. Tokyo: Research Institute for Languages and Cultures of Asia and Africa (ILCAA), Tokyo University of Foreign Studies.

Zimmer, Franz. n.d. [Matengo grammar sketch and dictionary]. Ms. 